\title{
Clinical correlates of social cognition after an ischemic stroke preliminary findings
}

\author{
Maria de Fátima Dias de Souza ${ }^{\oplus}$, Maíra Glória de Freitas Cardoso ${ }^{1 \oplus}$, Érica Leandro Marciano Vieira ${ }^{1}$, \\ Natália Pessoa Rocha ${ }^{\circledR}$, Talita Hélen Ferreira e Vieira ${ }^{3,4}$, Alberlúcio Esquirio Pessoa ${ }^{5 \odot}$, \\ Vinicius Sousa Pietra Pedroso ${ }^{1 \odot}$, Milene Alvarenga Rachid ${ }^{\bullet}$, Leonardo Cruz de Souza ${ }^{1}$, \\ Antônio Lúcio Teixeira ${ }^{7,8}{ }^{\bullet}$, Aline Mansueto Mourão ${ }^{9 \odot}$, Aline Silva de Miranda ${ }^{1,3} \odot$
}

\begin{abstract}
The co-occurrence of post-stroke behavioral disorders and cognitive impairment has been extensively investigated. However, studies usually do not include social cognition among the assessed cognitive domains. Objective: To investigate the potential association between facial emotion recognition, a measure of social cognition, and behavioral and cognitive symptoms in the subacute phase of ischemic stroke. Methods: Patients admitted to a Stroke Unit with ischemic stroke were followed up to 60 days. At this time point, they were evaluated with the following tools: Mini-Mental State Examination (MMSE); Frontal Assessment Battery (FAB); Visual Memory Test of the Brief Cognitive Battery (VMT); Phonemic Verbal Fluency (F-A-S Test); Digit Span; Facial Emotion Recognition Test (FERT) and Hospital Anxiety and Depression Scale (HADS). A control group composed of 21 healthy individuals also underwent the same evaluation. Results: Eighteen patients with ischemic stroke were enrolled in this study. They had similar age, sex and schooling years compared to controls. Depression symptoms and episodic memory deficits were significantly more frequent in patients compared to controls. The recognition of sadness expression positively correlated with the levels of anxiety and depression, while and the recognition of fear expression negatively correlated with depression in the stroke group. Conclusions: After an ischemic stroke, patients exhibit impairment in social cognition skills, specifically facial emotion recognition, in association with behavioral symptoms.
\end{abstract}

Keywords: cognition, cognitive dysfunction, neurobehavioral manifestations, depression, stroke.

\section{CORRELATOS CLÍNICOS DA COGNIÇÃO SOCIAL APÓS ACIDENTE VASCULAR CEREBRAL ISQUÊMICO: DESCOBERTAS PRELIMINARES}

RESUMO. A co-ocorrência de distúrbios comportamentais e comprometimento cognitivo pós-acidente vascular cerebral (AVC) é amplamente descrita na literatura. No entanto, os estudos geralmente não incluem a cognição social entre os domínios cognitivos avaliados. Objetivo: Investigar a potencial associação entre o reconhecimento da emoção facial, uma medida da cognição social, e os sintomas comportamentais e cognitivos na fase subaguda do AVC isquêmico. Métodos: Pacientes internados em uma Unidade de AVC com AVC isquêmico foram acompanhados até 60 dias, quando foram avaliados com os seguintes instrumentos: Mini-Exame do Estado Mental (MEEM); Bateria de Avaliação Frontal (FAB); Teste de Memória Visual da Bateria Cognitiva Breve (VMT); Fluência Verbal Fonêmica (Teste F-A-S); Span de dígitos; Teste de Reconhecimento de Emoção Facial (FERT) e Escala Hospitalar de Ansiedade e Depressão (HADS). Um grupo controle constituído por 21 indivíduos saudáveis também foi submetido à mesma avaliação. Resultados: Dezoito pacientes com AVC isquêmico foram incluídos no presente estudo, apresentando idade, sexo e anos de escolaridade semelhantes aos do grupo controle. Os sintomas de depressão e déficits de memória episódica foram significativamente mais frequentes em pacientes com AVC. 0 reconhecimento da expressão de tristeza correlacionou-se positivamente com os níveis de ansiedade e depressão, ao passo que o reconhecimento da expressão de medo correlacionou-se negativamente com depressão no grupo de AVC. Conclusões: Após um AVC isquêmico, pacientes podem apresentar alterações de cognição social, especificamente de reconhecimento da emoção facial, em associação com sintomas comportamentais.

Palavras-chave: cognição, disfunção cognitiva, manifestações neurocomportamentais, depressão, acidente vascular cerebral.

This study was conducted at the Interdisciplinary Laboratory of Medical Investigation, School of Medicine, Universidade Federal de Minas Gerais, Belo Horizonte, Brazil. ${ }^{1}$ Laboratório Interdisciplinar de Investigação Médica, Faculdade de Medicina, Universidade Federal de Minas Gerais - Belo Horizonte, MG, Brazil. ${ }^{2}$ The Mitchell Center for Alzheimer's Disease and Related Brain Disorders, Department of Neurology, McGovern Medical School, The University of Texas Health Science Center at Houston - Houston, TX, USA. ${ }^{3}$ Departamento de Morfologia, Instituto de Ciências Biológicas, Universidade Federal de Minas Gerais - Belo Horizonte, MG, Brazil. ${ }^{4}$ Departamento de Fisioterapia, Faculdade Sete Lagoas - Sete Lagoas, MG, Brazil. ${ }^{5}$ Hospital Metropolitano Odilon Behrens - Belo Horizonte, MG, Brazil. ${ }^{6}$ Departamento de Patologia, Instituto de Ciências Biológicas, Universidade Federal de Minas Gerais - Belo Horizonte, MG, Brazil. ${ }^{7}$ Santa Casa BH Ensino e Pesquisa - Belo Horizonte, MG, Brazil. ${ }^{8}$ Neuropsychiatry Program, Department of Psychiatry \& Behavioral Sciences, McGovern Medical School, University of Texas Health Science Center at Houston - Houston, TX, USA. 'Departamento de Fonoaudiologia, Faculdade de Medicina, Universidade Federal de Minas Gerais - Belo Horizonte, MG, Brazil.

Aline Mansueto Mourão and Aline Silva de Miranda. Universidade Federal de Minas Gerais. Av. Prof. Alfredo Balena, 190 - Santa Efigênia - $30130-100$ Belo Horizonte MG - Brazil. E-mail: alinemmourao@gmail.com; mirandaas@icb.ufmg.br and mirandas.aline@gmail.com

Disclosure: The authors report no conflicts of interest.

Funding: Fundação de Amparo à Pesquisa do Estado de Minas Gerais [grant number APQ-03539-13]

Received on October 18, 2020. Accepted in final form on December 29, 2020. 


\section{INTRODUCTION}

Stroke is a common, serious, and disabling global $S_{\text {health problem. The development of post-stroke }}$ behavioral disorders and cognitive impairment leads to worse clinical prognosis. ${ }^{1}$ Although these disorders have been extensively described following cerebral ischemic events, these studies usually do not include social cognition among the assessed cognitive domains. ${ }^{1-10}$

Social cognition refers to cognitive processes related to perception and interpretation of the social environment. ${ }^{11}$ For instance, the ability to recognize other person's emotions from his/her facial expression is essential for human interactions. ${ }^{12,13}$ Over the last two decades, the study of social cognition has gained greater attention in the literature. However, only a few studies evaluated facial emotion recognition after stroke, reporting decreased ability to recognize emotions in patients when compared with healthy controls. ${ }^{14-17}$ Moreover, these studies did not investigate potential interactions among behavior, general cognition and social cognition measures.

Identifying potential interactions among these discrete domains is a promising area of investigation, especially given the role played by these factors on rehabilitation and, hence, prognosis of patients with stroke.

Stroke significantly affects the life of the patient on multiple levels, including physical, cognitive, behavioral, and social ones. ${ }^{14}$ The current study focused on the evaluation of facial emotion recognition, a marker of social cognition, investigating whether it would be associated with a series of cognitive domains, as well as depression and anxiety symptoms in the subacute phase of ischemic stroke.

\section{METHODS}

\section{Participants}

This study is part of a research project approved by the Research Ethics Committee of the Universidade Federal de Minas Gerais (Project, CAAE: 02811212.5.3001.5129) and by the Research Ethics Committee of the Hospital Municipal Odilon Behrens (Number 2.515.900, February 27, 2018). Here, we present cross-sectional data on clinical assessments of behavior, cognition and social cognition (i.e., facial emotion recognition) of the study participants.

Eighteen patients who were followed up to 60 days after their stroke were enrolled in this study. Inclusion criteria were patients over 18 years old with the diagnosis of ischemic stroke. The exclusion criteria were: comorbidity with other neurological diseases (traumatic brain injury, epilepsy and other); neurodegenerative diseases; psychiatric disorders (schizophrenia, bipolar disorder, major depression, generalized anxiety and panic disorders); inflammatory (i.e. myelitis, sarcoidosis) and infectious diseases (HIV, neurosyphilis and others). Patients with altered level of consciousness according to the Glasgow Coma Scale ( $\leq 14)$ and aphasia according to the National Institutes of Health Stroke Scale (NIHSS) at admission were also excluded.

Healthy participants with comparable age, sex, and educational level were recruited from the local community (control group). This group comprised people with no previous diagnosis of stroke or any other neurological, neurodegenerative, psychiatric, inflammatory or infectious diseases. The recruitment process and study design are outlined in Figure 1.

\section{Clinical assessment}

The neuropsychological assessment of the stroke group was performed during an outpatient clinic visit between 45 and 60 days after the ictus. The following tools were applied: (i) the Mini-Mental State Examination (MMSE),

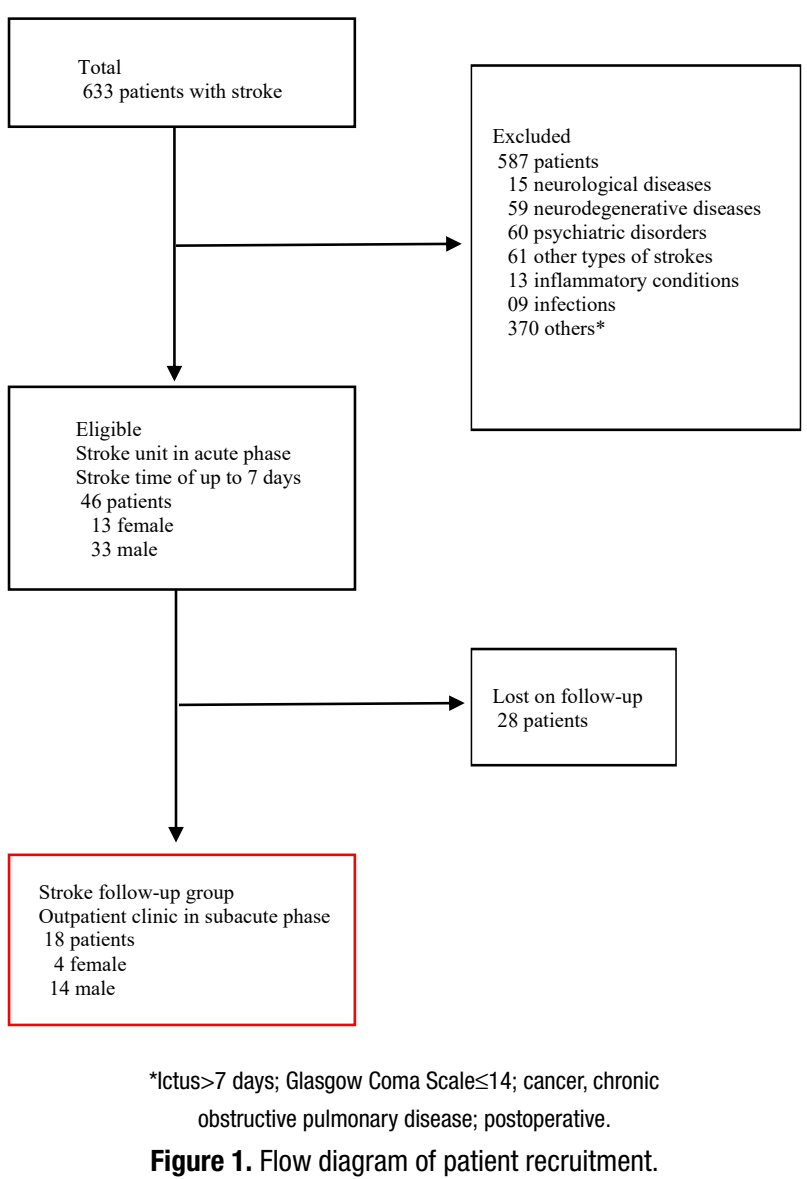


as a measure of general cognition; ${ }^{18,19}$ (ii) the Frontal Assessment Battery (FAB) for the evaluation of executive functions, including six subtests: similarities, lexical fluency (letter S), motor series, conflicting instructions, go/ no-go and prehension behavior; ${ }^{20}$ (iii) the Visual Memory Test of the Brief Cognitive Battery (VMT) ${ }^{21,22}$ that assesses incidental memory, immediate memory, learning, late recall and recognition; (iv) the Phonemic Verbal Fluency (F-A-S Test); ${ }^{23}$ (v) the Digit Span for attention and working memory; ${ }^{24}$ and (vi) the Facial Emotion Recognition Test (FERT) for social cognition. ${ }^{11,25}$

Besides cognitive tests, the Hospital Anxiety and Depression Scale (HADS) was used to detect symptoms of anxiety and depression. ${ }^{26}$ Neurological impairment was determined by the National Institutes of Health Stroke Scale (NIHSS) in the acute phase of the stroke. ${ }^{27}$

The same cognitive and behavioral battery was applied to controls.

\section{Statistical analysis}

Categorical variables were expressed as frequencies and percentages. A bilateral $p$ value lower than 0.05 was adopted as the level of significance for all statistical tests.

All variables were assessed for normality using the Shapiro-Wilk test, presenting a non-parametric distribution. Differences of sex and education between groups were tested by Pearson chi-square test. Differences of age and neuropsychological performance between groups were tested using the Mann-Whitney test.

A binary logistic regression was performed to determine which variables were significantly associated with stroke. A backward stepwise regression was used, and the following variables were included in the initial model: age, sex, FERT total score, HADS anxiety, HADS depression and VMT late recall. The backward stepwise selection was automatically performed using the SPSS software version 26.0 (SPSS Inc., Chicago, IL, USA), and the removal testing was based on the probability of the likelihood-ratio statistic based on conditional parameter estimates. The goodness of fit of the logistic regression model was assessed by the Hosmer-Lemeshow test, as well as a Receiver Operating Characteristic (ROC) curve.

To identify individuals with suggestive clinical anxious and depressive scores on HADS, a clinical cutoff score of 6 was used for HAD-D ${ }^{26}$ and of 7 for HAD-A. ${ }^{28}$ The Fisher's exact test was applied to investigate differences in prevalence of anxiety and depression between groups.

\section{RESULTS}

Table 1 shows sociodemographic characteristics and neuropsychological performance of stroke and control groups. Patients and controls have similar age, sex and educational level. Post-stroke patients had worse depressive symptoms and worse cognitive performance in cognitive domains than controls.

The mean NIHSS of the stroke group was 3.56 \pm 2.00 , without any correlation with behavior, cognitive and social cognition tests.

Although there was no significant difference between patients and controls in FERT scores, we observed that among patients the recognition of sadness expression positively correlated with the levels of anxiety (Spearman's rank correlation coefficient $[\mathrm{rho}]=0.587, \mathrm{p}<0.05$ ) and depression $(r h o=0.598, p<0.01)$. Conversely, the recognition of fear expression negatively correlated with depression symptoms in the stroke group (rho $=0.481$, $\mathrm{p}<0.05$ ) (Table 2). In addition, VMT recall positively correlated with FERT neutral ( $r h o=0.523, p=0.026)$ and FERT total scores ( $r h o=0.478, p<0.05)$, and VMT recognition positively correlated with FERT total score (rho=0.554, $\mathrm{p}=0.017)$. These correlations were not found in controls.

A binary logistic regression was performed in order to ascertain the variables significantly associated with stroke in a multivariate analysis. In the final model (step 4), the variables that remained significantly associated with stroke were: a higher score in the HADS-A, a lower score on VMT late recall, and sex (being male) (Table 3). The logistic regression model was significant [Hosmer-Lemeshow goodness of fit test (step 4): chisquare=3.930; $\mathrm{p}=0.788$ ], and the predicted variability resulted in an area under the curve (AUC) of 0.877 in the ROC analysis (Figure 2).

\section{DISCUSSION}

As far as we are concerned, this is the first study that investigated potential interactions between social cognition (i.e., facial emotion recognition) and poststroke behavior (depression and anxiety) and cognitive (episodic memory and executive functions) symptoms. As previously reported, ${ }^{15-17,29,30,31}$ after an ischemic stroke, patients present with worse cognitive performance of immediate memory, late recall, recognition, and more depressive symptoms than healthy controls. There was no difference between stroke patients and healthy individuals in their ability to recognize facial emotion. However, the recognition of sadness expression positively correlated with the levels of anxiety and depression, while the recognition of fear expression negatively correlated with depression symptoms in the stroke group. Among cognitive variables, the recognition of neutral faces and FERT total score correlated 
Table 1. Sociodemographic characteristic and neuropsychological performance of stroke follow-up and control groups.

\begin{tabular}{|c|c|c|c|c|}
\hline & & $\begin{array}{c}\text { Control } \\
n=21 \\
n(\%) \\
\text { median (percentile } \\
25-75)\end{array}$ & $\begin{array}{c}\text { Post-stroke } \\
n=18 \\
n(\%) \\
\text { median (percentile } \\
25-75)\end{array}$ & p-value \\
\hline \multicolumn{5}{|c|}{ Sociodemographic characteristic } \\
\hline \multirow{2}{*}{ Gender } & Male & $13(62 \%)$ & $14(78 \%)$ & $0.284^{*}$ \\
\hline & Female & $8(38 \%)$ & $4(22 \%)$ & \\
\hline \multirow{6}{*}{ Education } & Illiterate & $1(5 \%)$ & $1(6 \%)$ & $0.921^{*}$ \\
\hline & $1-4$ years of schooling & $5(24 \%)$ & $3(17 \%)$ & \\
\hline & $5-8$ years of schooling & $7(33 \%)$ & $6(33 \%)$ & \\
\hline & $9-10$ years of schooling & $0(0 \%)$ & $1(5 \%)$ & \\
\hline & 11 years of schooling & $7(33 \%)$ & $6(33 \%)$ & \\
\hline & More than 11 years of schooling & $1(5 \%)$ & $1(6 \%)$ & \\
\hline \multirow{2}{*}{ Age (years) } & Mean \pm DPM & $63.43 \pm 9.89$ & $62.89 \pm 11.74$ & $0.799^{+}$ \\
\hline & (Minimum-maximum) & $(39-80)$ & $(33-84)$ & \\
\hline \multicolumn{5}{|c|}{ Behavior, cognitive and social cognition tests } \\
\hline Anxiety & HADS_A & $3(2.50-5.00)$ & $8(2.00-10.00)$ & $0.057^{+}$ \\
\hline Depression & HADS_D & $2(0.00-4.00)$ & $5(1.75-7.50)$ & $0.031^{+}$ \\
\hline Cognitive deficits & MEEM & $28(26.00-29.00)$ & $29(27.75-30.00)$ & $0.161^{+}$ \\
\hline Executive functions & FAB & $17(16.00-17.00)$ & $17(14.75-17.25)$ & $0.712^{+}$ \\
\hline \multirow{5}{*}{ Visual memory test } & VMT_incidental_memory & $8(7.50-9.50)$ & $8(5.75-9.00)$ & $0.101^{+}$ \\
\hline & VMT_immediate_memory & $10(9.00-10.00)$ & $8(7.00-9.00)$ & $0.002^{+}$ \\
\hline & VMT_learning & $10(9.00-10.00)$ & $9(8.00-10.00)$ & $0.084^{+}$ \\
\hline & VMT_late recall & $10(8.50-10.00)$ & $8.5(8.00-9.25)$ & $0.044^{+}$ \\
\hline & VMT_recognition & $10(10.00-10.00)$ & $10(9.75-10.00)$ & $0.025^{+}$ \\
\hline \multirow{4}{*}{ Phonemic verbal fluency } & FAS_animals & $14.5(12.25-16.75)$ & $14(11.00-15.25)$ & $0.527^{+}$ \\
\hline & FAS_F & $8(4.50-11.00)$ & $7.5(4.75-11.00)$ & $0.821^{+}$ \\
\hline & FAS_A & $9(6.50-12.00)$ & $8.5(5.00-10.00)$ & $0.343^{+}$ \\
\hline & FAS_S & $10(6.00-12.00)$ & $8.5(5.00-13.00)$ & $0.799^{+}$ \\
\hline \multirow{4}{*}{$\begin{array}{l}\text { Attention and working } \\
\text { memory }\end{array}$} & DS_order_direct_right & $8(6.00-9.00)$ & $9(7.75-9.25)$ & $0.209^{+}$ \\
\hline & DS_order_direct_span & $5(4.00-6.00)$ & $6(5.00-6.00)$ & $0.187^{+}$ \\
\hline & DS_order_reverse_acertos & $3(2.00-4.00)$ & $4(2.00-5.00)$ & $0.283^{+}$ \\
\hline & DS_order_reverse_span & $3(2.00-3.00)$ & $3(2.00-4.00)$ & $0.279^{+}$ \\
\hline Social cognition & FERT & $24(21.50-27.50)$ & $24.5(22.00-27.25)$ & $0.745^{+}$ \\
\hline
\end{tabular}

n: number of patients; DPM: Average Standard Deviation; MEEM: Mini-Mental State Examination; FAB: Frontal Assessment Battery; HADS: Hospital Anxiety and Depression Scale; HADS_A: Anxiety subscale; HADS_D: Depression subscale; VMT: Visual Memory Test of the Brief Cognitive Battery; VMT_incidental_memory: VMT incidental memory; VMT_immediate_memory: VMT immediate memory; VMT_learning:VMT learning; VMT_late recall:VMT late recall; VMT_recognition: VMT recognition; FAS: Verbal Fluency Task; FAS_animals: FAS semantic category for animals; FAS_F: FAS production of words beginning with F; FAS_A: FAS production of words beginning with A; FAS_S: FAS production of words beginning with S; FERT: Facial Emotion Recognition Test; *Pearson's chi-square test; 'Mann-Whitney test.

positively with VMT recall, and FERT total score positively correlated with VMT recognition.

Contrary to our findings, Nijsse et al. reported significant differences between stroke patients and controls on FERT performance. Besides using a longer version of the FERT (60 vs. 25 figures in the current study), their patients had a stroke at least three years before the assessment. ${ }^{32}$ They also found that FERT scores correlated positively to behavioral problems reported by the Dysexecutive Questionnaire. Our results indicate 
Table 2. Spearman correlation between Facial Emotion Recognition Test with cognitive and behavioral tests at stroke follow-up group ( $n=18)$.

\begin{tabular}{lcccccc}
\hline FERT & HADS anxiety & HADS depression & MMSE & Fluency A & VMT recall & VMT recognition \\
\hline Surprise & 0.185 & 0.082 & 0.209 & 0.074 & -0.119 & 0.103 \\
\hline Disgust & 0.346 & 0.019 & 0.072 & 0.125 & 0.396 & 0.090 \\
\hline Fear & -0.015 & $\mathbf{- 0 . 4 8 1 ^ { \star }}$ & -0.103 & -0.010 & 0.275 & 0.092 \\
\hline Anger & 0.332 & 0.125 & -0.057 & 0.338 & -0.030 & 0.322 \\
\hline Sadness & $\mathbf{0 . 5 8 7 ^ { \star }}$ & $\mathbf{0 . 5 9 8 * \star}$ & 0.134 & 0.262 & 0.077 & 0.302 \\
\hline Neutral & -0.110 & -0.398 & $\mathbf{0 . 4 7 4}$ & 0.439 & $\mathbf{0 . 5 2 3}^{\star}$ & 0.168 \\
\hline FERT total & $\mathbf{0 . 5 6 5 ^ { * }}$ & -0.010 & 0.285 & $\mathbf{0 . 5 4 2}^{\star}$ & $\mathbf{0 . 4 7 8}^{\star}$ & $\mathbf{0 . 5 5 4}^{\star}$ \\
\hline
\end{tabular}

FERT: Facial Emotion Recognition Test; HADS: Hospital Anxiety and Depression scale; MMSE: Mini-Mental State Examination; VMT: Visual Memory Test of the Brief Cognitive Battery — happiness was not included because it was constant among all participants (all scored total); ${ }^{\star} p<0.05 ;{ }^{\star *} p<0.01$.

Table 3. Final logistic regression model to predict stroke (step 4).

\begin{tabular}{lcccccccc}
\hline \multirow{2}{*}{ Predictive variable } & \multirow{2}{*}{ B } & \multirow{2}{*}{ SE } & Wald & \multirow{2}{*}{ df } & p-value & \multirow{2}{*}{ Odds Ratio } & \multicolumn{2}{c}{ 95\%Cl for Odds Ratio } \\
\hline Sex & 2.161 & 1.033 & 4.737 & 1 & 0.037 & 8.680 & 1.145 & 65.788 \\
\hline HADS A & 0.394 & 0.150 & 6.940 & 1 & 0.008 & 1.483 & 1.106 & 1.989 \\
\hline VMT late recall & -1.153 & 0.450 & 6.570 & 1 & 0.010 & 0.316 & 0.131 & 0.762 \\
\hline
\end{tabular}

B: B coefficient; SE: standard error; df: degrees of freedom; 95\%Cl: 95\% confidence interval; HADS A: anxiety subscale; VMT: Visual Memory Test of the Brief Cognitive Battery.

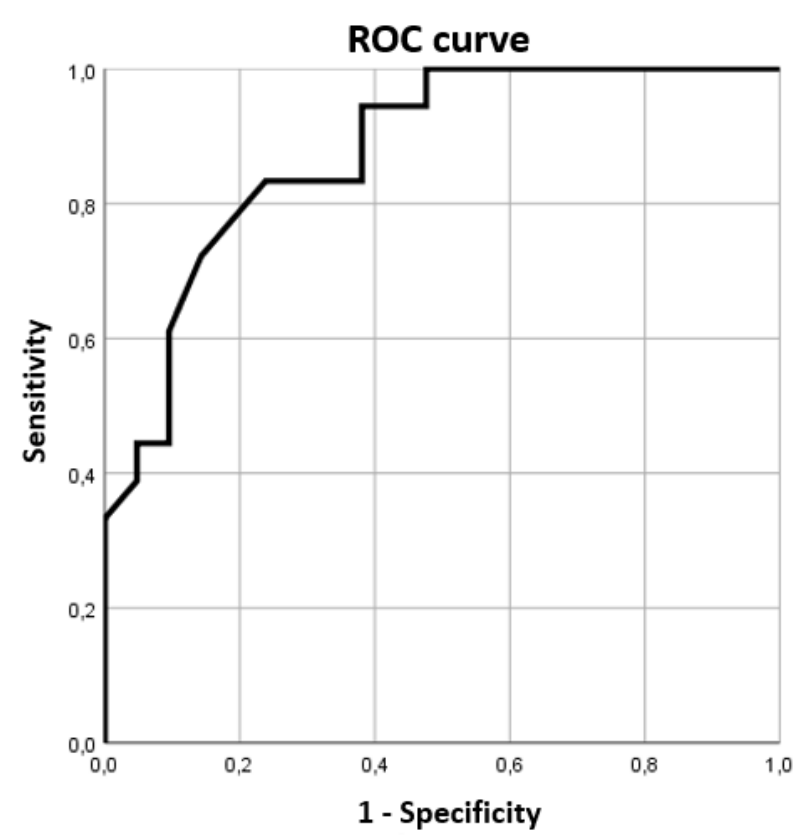

ROC: Receiver Operating Characteristic.

Figure 2. Receiver Operating Characteristic curve of predicted variability (AUC=0.877).

that stroke, even with mild neurological impairment, is associated with memory deficits. More specifically, it confirms data on the emergence of post-stroke cognitive deficits without clear association with motor, sensory, or language deficits. ${ }^{2}$ Data from previous studies show that patients suffering from stroke have diminished ability to recognize facial, prosodic and lexical emotions in subacute and chronic phases, but the degree of neurological impairment was not considered (for a review, see Yuvaraj et al. The profile of mild neurological impairment in our patients may explain the absence of differences between patients in the subacute phase of the stroke and healthy individuals in their ability to recognize facial emotion.

Impairment in immediate memory, recall, and recognition was evidenced by the VMT, suggesting genuine memory deficits, not a change due to deficits in other cognitive domains, such as attention. ${ }^{33}$ Similar to our findings, Karimian et al. found that visual memory was the most impaired domain in patients in the chronic phase of the stroke as compared to healthy controls. ${ }^{34}$ Therefore, cognitive deficits start in the acute phase of stroke, remain in the subacute and chronic phases, and can progress to dementia. ${ }^{1-4,6,7,10}$

We found that stroke patients present high scores in HADS depression and anxiety subscales when compared to controls. Anxiety and depression are common in patients in the acute, subacute and chronic phases of the stroke..$^{30,31,35,36}$ Actually, these are highly correlated constructs as shown here and by others. ${ }^{5,6,29,37,38}$ Among stroke patients, the higher the score in the HADS-A and HADS-DD, the worse the performance in the sadness and fear recognition of FERT, respectively. Our results are consistent with the literature showing that deficits 
in the ability to identify others' facial emotions are associated with mood disorders. ${ }^{39,40}$

Beyond facial emotion recognition, other aspects, not evaluated in our study, such as theory of mind (TOM), social decision making and empathy are also important for social cognition. ${ }^{32,41}$ Even three to four years after a stroke, deficits in social cognition were found in patients, specifically in tasks of emotion recognition, TOM and of behavior regulation and inhibition. ${ }^{32}$ A more comprehensive assessment of social cognition, including other domains such as TOM, empathy, social decision making and behavior regulation, could have provided relevant information about deficits in the subacute phase of stroke, prompting earlier interventions.

In addition to anxiety, the score at the VMT late recall was significantly associated with stroke in the multivariate analysis. Greater decline in episodic memory was significantly associated to anxiety in a prospective study with healthy older individuals, suggesting that anxiety may be a predictor for cognitive decline..$^{42}$ Among stroke patients with lesion in left hemisphere, lower episodic memory score was a significant predictor of higher anxiety scores one to three months after a stroke. ${ }^{43}$ Moreover, worse episodic verbal memory performance was a significant predictor of both higher anxiety and depression scores in patients three months after a stroke. ${ }^{44}$ These data indicate that anxiety is associated with episodic memory performance in the subacute phase of stroke. Studies with longitudinal design should confirm a causal link between them.

The results of the study must be interpreted in light of its limitations, including sample size and lack of neuroimaging assessment. In addition, it would have been of value to include patients with different levels, i.e. mild, moderate and severe, of neurological impairment. As shown by Circelli et al., changes in the prefrontal cortex, clinically observed through impaired performance on tasks of executive functioning, were associated with changes in visual scanning patterns for recognition of face emotions. ${ }^{45}$ Future research should better explore how neuropsychological performance and social cognition correlate, incorporating neuroimaging and neurophysiological information.

The current study supports the premise that poststroke social cognition deficits should not be neglected, paving the way for future research with a focus on multidisciplinary prognosis and effective rehabilitation in order to achieve better recovery and favorable outcomes for these patients.

Authors' contributions. MFDS: conceptualization, formal analysis, methodology, validation, visualization, writing - original draft. MGFC: conceptualization, formal analysis, investigation, methodology, supervision, validation, visualization, writing - original draft. ELMV. conceptualization, methodology, project administration, validation, visualization. NPR: conceptualization, formal analysis, investigation, methodology, supervision, validation, visualization, writing - review \& editing. THFV: methodology, validation, visualization, writing - review \& editing. AEP: conceptualization, data curation, investigation, methodology, validation, visualization. VSPP: conceptualization, data curation, investigation, methodology, validation, visualization. MAR: conceptualization, investigation, methodology, supervision, validation, visualization. LCS: conceptualization, investigation, methodology, supervision, validation, visualization, writing - review \& editing. ALT: conceptualization, data curation, formal analysis, funding acquisition, project administration, resources, supervision, validation, visualization, writing — review \& editing. AMM: conceptualization, formal analysis, methodology, validation, visualization, writing-original draft, writing - review \& editing. ASM: conceptualization, data curation, formal analysis, funding acquisition, investigation, methodology, project administration, resources, supervision, validation, visualization, writing - review \& editing.

\section{REFERENCES}

1. Douven E, Aalten P, Staals J, Schievink SH, van Oostenbrugge RJ, Verhey $\mathrm{FR}$, et al. Co-occurrence of depressive symptoms and executive dysfunction after stroke: Associations with brain pathology and prognosis. J Neurol Neurosurg Psychiatry. 2018;89(8):859-65. https://doi.org/10.1136/ jnnp-2017-317548

2. Planton M, Peiffer S, Albucher JF, Barbeau EJ, Tardy J, Pastor J, et al. Neuropsychological outcome after a first symptomatic ischaemic stroke with 'good recovery'. Eur J Neurol. 2012;19(2):212-9. https://doi.org/10.1111/j.1468-1331.2011.03450.x

3. Oliveira CR, Pagliarin KC, Calvette LF, Gindri G, Argimon II, Fonseca RP. Depressive signs and cognitive performance in patients with a right hemis-

phere stroke. CoDAS. 2015;27(5):452-7. https://doi.org/10.1590/23171782/20152015005

4. Yoshda HM, Barreira J, Fernandes PT. Motor skills, depressive symptoms and cognitive functions in post-stroke patients. Fisioter Pesq 2019;26(1):9-14. https://doi.org/10.1590/1809-2950/17001026012019

5. Ayerbe L, Ayis S, Crichton S, Wolfe CD, Rudd AG. The long-term outcomes of depression up to 10 years after stroke: The South London Stroke Register. J Neurol Neurosurg Psychiatry. 2014;85(5):514-21. https://doi. org/10.1136/jnnp-2013-306448

6. Sibolt G, Curtze S, Melkas S, Pohjasvaara T, Kaste M, Karhunen PJ, et al. Post-stroke depression and depression-executive dysfunction syndrome 
are associated with recurrence of ischaemic stroke. Cerebrovasc Dis. 2013;36(5-6):336-43. https://doi.org/10.1159/000355145

7. Dichgans $M$, Leys D. Vascular cognitive impairment. Circ Res. 2017;120(3):573-91. https://doi.org/10.1161/CIRCRESAHA.116.308426

8. Douven E, Schievink SH, Verhey FR, van Oostenbrugge RJ, Aalten P, Staals J, et al. The Cognition and Affect after Stroke - a Prospective Evaluation of Risks (CASPER) study: Rationale and design. BMC Neurol. 2016;16(65):1-11. https://doi.org/10.1186/s12883-016-0588-1

9. Ferreira MG, Moro CH, Franco SC. Cognitive performance after ischaemic stroke. Dement Neuropsychol. 2015;9(2):165-75. https://doi.org/10.1590/ 1980-57642015DN92000011

10. Antipova D, Eadie L, Macaden A, Wilson P. Diagnostic accuracy of clinical tools for assessment of acute stroke: a systematic review. BMC Emerg Med. 2019;19:49. https://doi.org/10.1186/s12873-019-0262-1

11. Mariano LI, Caramelli P, Guimarães HC, Gambogi LB, Moura MV, Yassuda MS, et al. Can social cognition measurements differentiate behavioral variant frontotemporal dementia from Alzheimer's disease regardless of apathy? J Alzheimer's Dis. 2020;1:1-11. https://doi.org/10.3233/JAD190861

12. Tippett, DC, Godin BR, Oishi K, Oishi K, Davis C, Gomez Y, et al. Impaired recognition of emotional faces after stroke involving right amygdala or insula. Semin Speech Lang. 2018;39(1):87-100. https://doi. org/10.1055/s-0037-1608859

13. Park S, Kim T, Shin SA, Kim YK, Sohn BK, Park HJ, et al. Behavioral and neuroimaging evidence for facial emotion recognition in elderly Korean adults with mild cognitive impairment, Alzheimer's disease, and frontotemporal dementia. Front Aging Neurosci. 2017;9:389. https://doi. org/10.3389/fnagi.2017.00389

14. Yuvaraj R, Murugappan M, Norlinah MI, Sundaraj K, Khairiyah M. Review of emotion recognition in stroke patients. Dement Geriatr Cogn Disord. 2013;36(3-4):179-96. https://doi.org/10.1159/000353440

15. Braun M, Traue H, Frisch S, Deighton R, Kessler H. Emotion recognition in stroke patients with left and right hemispheric lesion: results with a new instrument -the FEEL Test. Brain Cogn. 2005;58(2):193-201. https://doi org/10.1016/j.bandc.2004.11.003

16. Harciarek M, Heilman M, Jodzio K. Defective comprehension of emotional faces and prosody as a result of right hemisphere stroke: modality versus emotion-type specificity. J Int Neuropsychol Soc. 2006;12(6):774-81. https://doi.org/10.1017/S1355617706061121

17. Blonder L, Pettigrew L, Kryscio R. Emotion recognition and marital satisfaction in stroke. J Clin Exp Neuropsychol. 2012;34(6):634-42. https:// doi.org/10.1080/13803395.2012.667069

18. Brucki SM, Nitrini R, Caramelli P, Bertolucci $\mathrm{PH}$, Okamoto $\mathbb{H}_{\text {. Sugges- }}$ tions for utilization of the mini-mental state examination in Brazil. Arg Neuro-Psiquiatr. 2003;61(3):777-81. https://doi.org/10.1590/s0004282x2003000500014

19. Brucki SM, Rocha MS. Category fluency test: effects of age, gender and education on total scores, clustering and switching in Brazilian Portuguese-speaking subjects. Braz J Med Biol Res. 2004;37(12):1771-7. https:// doi.org/10.1590/s0100-879x2004001200002.

20. Beato R, Amaral-Carvalho V Guimarães HC, Tumas V Souza CP Oliveira GN, et al. Frontal assessment battery in a Brazilian sample of healthy controls: normative data. Arq Neuro-Psiquiatr. 2012;70(4):278-80. https:// doi.org/10.1590/s0004-282x2012005000009.

21. Castro S, Damin AE, Porto CS, Caramelli P, Nitrini R. The abbreviated form of the Brief Cognitive Battery in the diagnosis of dementia in Alzheimer's disease. Dement Neuropsychol. 2009;3(4):327-31. https://doi. org/10.1590/S1980-57642009DN30400011.

22. Nitrini $\mathrm{R}$, Lefèvre $\mathrm{BH}$, Mathias SC, Caramelli P, Carrilho PE, Sauaia N, et al. Brief and easy-to-administer neuropsychological tests in the diagnosis of dementia. Arq Neuro-Psiquiatr. 1994;52(4):457-65. https://doi. org/10.1590/s0004-282x1994000400001

23. Machado TH, Fichman HC, Santos EL, Carvalho VA, Fialho PP, Koenig AM, et al. Normative data for healthy elderly on the phonemic verbal fluency task - FAS. Dement Neuropsychol. 2009;3(1):55-60. https://doi. org/10.1590/S1980-57642009DN30100011

24. Figueiredo VL, Nascimento E. Performances in the forward and backward digit span in the WISC-III and WAIS-III. Psic: Teor e Pesq. 2007;23(3):3138. https://doi.org/10.1590/S0102-37722007000300010

25. Bertoux M, de Souza LC, Sarazin M, Funkiewiez A, Dubois B, Hornberger M. How preserved is emotion recognition in Alzheimer disease compared with behavioral variant frontotemporal dementia? Alzheimer Dis Assoc Disord. 2015;29(2):154-7. https://doi.org/10.1097/ WAD 0000000000000023
26. Pedroso VS, Vieira EL, Brunoni AR, Lauterbach EC, Teixeira AL. Psychopathological evaluation and use of the hospital anxiety and depression scale in a sample of Brazilian patients with post-stroke depression. Arch Clin Psychiatry. 2016;43(6):147-50. https://doi.org/10.1590/010160830000000102

27. Cincura C, Pontes-Neto OM, Neville IS, Mendes HF, Menezes DF, Mariano DC, et al. Validation of the National Institutes of Health Stroke Scale, modified Rankin Scale and Barthel Index in Brazil: the role of cultural adaptation and structured interviewing. Cerebrovasc Dis. 2009;27(2):119-22. https:// doi.org/10.1159/000177918

28. Wichowicz HM, Wieczorek D. Badanie. przesiewowe depresji poudarowej z uzyciem Hospital Anxiety and Depression Scale (HADS). Psychiatr Pol. 2011;45(4):505-14

29. Pedroso VS, Brunoni AR, Vieira ÉL, Jorge RE, Lauterbach EC, Teixeira AL. Early psychiatric morbidity in a Brazilian sample of acute ischemic stroke patients. Clinics. 2018;73:1-5. https://doi.org/10.6061/clinics/2018/e055

30. De Mello RF, Santos IS, Alencar AP Benseñor IM, Lotufo PA, Goulart AC. Major depression as a predictor of poor long-term survival in a Brazilian stroke cohort (study of stroke mortality and morbidity in adults) EMMA study. J Stroke Cerebrovasc Dis. 2016;25(3):618-25. https://doi. org/10.1016/j.jstrokecerebrovasdis.2015.11.021

31. Rafsten L, Danielsson A, Sunnerhagen KS. Anxiety after stroke: a systematic review and meta-analysis. J Rehabil Med. 2018;50(9):769-78. https://doi.org/10.2340/16501977-2384

32. Nijsse B, Spikman JM, Visser-Meily JM, de Kort PL, van Heugten CM. Social cognition impairments are associated with behavioural changes in the long term after stroke. PLoS One. 2019;14(3):e0213725. https://doi. org/10.1371/journal.pone.0213725

33. Grober E, Buschke H. Genuine memory deficits in dementia. Dev Neuropsychol. 1987;3(1):13-36. https://doi.org/10.1080/87565648709540361

34. Karimian N, Asgari K, Neshat Doost HT, Oreizi HR, Najafi MR. Investigating patterns of memory impairment in ischemic stroke in an Iranian population. Appl Neuropsychol Adult. 2018;25(5):458-63. https://doi.org/10.1080/2 3279095.2017.1329144

35. Limampai P, Wongsrithep W, Kuptniratsaikul V. Depression after stroke at 12-month follow-up: a multicenter study. Int J Neurosci. 2017:127(10):887-92. https://doi.org/10.1080/00207454.2016.1277344

36. Mitchell AJ, Sheth B, Gill J. Prevalence and predictors of post-stroke mood disorders: a meta-analysis and meta-regression of depression, anxiety and adjustment disorder. Gen Hosp Psychiatry. 2017;47:48-60. https:// doi.org/10.1016/j.genhosppsych.2017.04.001

37. Wright F, Wu S, Chun HY, Mead G. Factors associated with poststroke anxiety: a systematic review and meta-analysis. Stroke Res Treat. 2017;2017:2124743. https://doi.org/10.1155/2017/2124743

38. Cai W, Mueller C, Li YJ, Shen WD, Stewart R. Post stroke depression and risk of stroke recurrence and mortality: a systematic review and meta-analysis. Ageing Res Rev. 2019;50:102-9. https://doi.org/10.1016/j. arr.2019.01.013

39. Schaefer KL, Baumann J, Rich BA, Luckenbaugh DA, Zarate CA. Perception of facial emotion in adults with bipolar or unipolar depression and controls. J Psychiatr Res. 2010;44(16):1229-35. https://doi.org/10.1016/j. jpsychires.2010.04.02.4

40. LeMoult J, Sherdell JJ, Wright Y, Gotlib IH. Identification of emotional facial expressions following recovery from depression. J Abnorm Psychol. 2009;118(4):828-33. https://doi.org/10.1037/a0016944

41. Njomboro P. Social cognition deficits: current position and future directions for neuropsychological interventions in cerebrovascular disease. Behav Neurol. 2017;2017:2627487. https://doi.org/10.1155/2017/2627487

42. Fung AW, Lee JS, Lee AT, Lam LC. Anxiety symptoms predicted decline in episodic memory in cognitively healthy older adults: A 3-year prospective study. Int J Geriatr Psychiatry. 2018;33(5):748-54. https://doi.org/10.1002/ gps.4850

43. Lo Buono V, Bonanno L, Palmeri R, Corallo F, Parisi S, Trinchera A, et al. Relation among psychopathological symptoms, neuropsychological domains, and functional disability in subacute poststroke rehabilitation. J Stroke Cerebrovasc Dis. 2018;27(5):1381-5. https://doi.org/10.1016/j. jstrokecerebrovasdis.2017.12.033

44. Barker-Collo SL. Depression and anxiety 3 months post stroke: prevalence and correlates. Arch Clin Neuropsychol. 2007;22(4):519-31. https://doi. org/10.1016/j.acn.2007.03.002

45. Circelli KS, Clark US, Cronin-Golomb A. Visual scanning patterns and executive function in relation to facial emotion recognition in aging. Neuropsychol Dev Cogn B Aging Neuropsychol Cogn. 2013;20(2):148-73. https://doi.org/10.1080/13825585.2012.675427 